\title{
Corrosion Inhibition of Mild Steel in $11 \%$ Hydrochloric Acid Solutions by Using Black Pepper (Piper Nigrum)
}

\author{
MOHAMED NURI RAHUMA, HATEM AMER and MAJDE ALFERGANI \\ Faculty of Science, Chemistry Department, University of Benghazi, Libya \\ moh_n_r@yahoo.co.uk
}

Received 10 October 2013 / Revised 19 December 2013 / Accepted 2 January 2014

\begin{abstract}
The corrosion behavior of mild steel in $11 \%$ hydrochloric acid solution $(\mathrm{HCl})$ and the effect of using black pepper as a corrosion inhibitor has been studied. Specimens were exposed in the acidic media for maximum five days and corrosion rates evaluated, using the weight loss method. The results indicate that the black pepper functioned as a good corrosion inhibitor in this environment and inhibition efficiency increased with increasing the inhibitor concentration. The effect of temperature from $25^{\circ} \mathrm{C}$ to $45^{\circ} \mathrm{C}$ revealed an increase in inhibition efficiency with rise in temperature and activation energies decreased in the presence of the inhibitor. Moreover, the thermodynamic parameters of the adsorption process free energy of adsorption, enthalpy and entropy were calculated the values of these parameters showed good interaction. The order of the reaction obtained from graph between logarithm concentration of inhibitor vs. logarithm corrosion rate of mild steel indicts that it is first order reaction.
\end{abstract}

Keywords: Mild steel, Hydrochloric acid, Corrosion inhibition, Black pepper, Weight loss tech, Langmuir kinetic parameters

\section{Introduction}

The word corrosion stands for material deterioration or surface damage in an aggressive environment ${ }^{1}$. Mild steel which is widely applied as the constructional material in many industries due to its excellent mechanical properties and low cost but it can be corroded in many environments ${ }^{2}$. Corrosion has been classified (I) Dry corrosion: occurs in the absence of a liquid phase usually at high temperature. (II) Wet corrosion: occurs when a liquid is present, this usually involves aqueous solutions or electrolytes and accounts for the greatest amount of corrosion ${ }^{3}$. In electrochemical cells or electrochemical corrosion there are four basic components. (i) The anode (oxidation reaction or real corrosion reaction take place). (ii) The cathode (reduction reaction take place). (iii) The electrolyte solution is an electrical conductive. (iv) electrical connection between the anode and cathode electrodes ${ }^{1}$.

There are many classification of electrochemical corrosion it can be classified to eight forms according to Fontana classification ${ }^{3}$. (1) Uniform, or general attack; its normally characterized by a chemical or electrochemical reaction that proceeds uniform over the 
entire exposed surface or over a large area. (2) Galvanic, or Bi-metallic corrosion; a potential difference usually exists between usually two dissimilar metals immersed in corrosive or conductive solution $^{3}$. (3) Crevice corrosion; intensive localized corrosion frequently occurs within crevices and other shielded areas on metal surfaces exposed to corrosives. (4) Pitting; is a form of extremely localized attack that results in holes in the metal. (5) Intergranular corrosion; grain boundary effects are of little or no consequence in most applications or uses of metals ${ }^{3}$. (6) Selective leaching, or parting; is the removal of one element from an alloy by corrosion processes. (7) Erosion corrosion; is the acceleration or increase in rate of deterioration or attack on a metal. (8) Stress corrosion cracking; refers to cracking caused by the simultaneous presence of tensile stress and a specific corrosive medium ${ }^{3}$. Acids are used in many chemical and petrochemical industries, hydrochloric acid which is widely used in the pickling, cleaning and descaling of steel and ferrous alloys ${ }^{4}$, when a pure iron coming in contact with hydrochloric acid, the resulting chemical reaction is obvious, with the solution beginning to bubble violently. The reaction can be expressed as follows:

$$
\mathrm{Fe}+2 \mathrm{HCl} \rightarrow \mathrm{FeCl}_{2}+\mathrm{H}_{2} \uparrow
$$

It can be seen that the result of this reaction by the gradual disappearance of the iron and the hydrogen bubbles rising rapidly to the surface. On an electrochemical level, there is also an exchange of electrons taking place 5 .

$$
\mathrm{Fe}+2 \mathrm{H}^{+}+2 \mathrm{Cl}^{-} \rightarrow \mathrm{Fe}^{2+}+2 \mathrm{Cl}^{-}+\mathrm{H}_{2} \uparrow
$$

There are three primary reasons for concern about and study of corrosion: safety, conservation and economics ${ }^{5}$. Corrosion has a very high cost associated to it. According to the US Federal Highway Administration (USFHA), corrosion costs the US economy \$276 billion each year (3.1\% of US GDP). About half of this cost is direct (approximately $\$ 137.9$ billion). The other half include indirect costs such as lost productivity, lost revenue from supply disruptions, labor to manage corrosion reduction, additional equipment to decrease corrosion, and the loss of reliability ${ }^{6}$.

There are many ways for corrosion prevention like: selecting a material that does not corrode in the actual environment, using a design that will avoid corrosion, changing, applying coatings on the metal surface and changing the environment, e.g. removing the oxygen or adding anticorrosion chemicals (inhibitors) ${ }^{7}$. The use of inhibitor is one of the most practical methods for protecting against corrosion and it is becoming increasingly popular ${ }^{8}$.

Most of the well-known acid inhibitors are organic compounds containing nitrogen, sulphur and/or oxygen atoms. It has been reported that many heterocyclic compounds containing hetero atoms like $\mathrm{N}, \mathrm{O}, \mathrm{S}$, have been proved to be effective inhibitor for the corrosion of steel in acid media ${ }^{9}$.

These organic compounds adsorb on metallic surface and then decrease the corrosion rate ${ }^{10}$. The efficiency of corrosion inhibitors depends on the mechanical, structural and chemical properties of the layer formed ${ }^{8}$. The natural inhibitor that we used in this work is black pepper is the fruit of Piper nigrum- $\mathrm{L}$ and is produced chiefly in India and Indonesia ${ }^{11}$. Pepper belongs to the piperaceae family, it's one of the oldest classic spices $^{12}$.

University of Hawai'i at Mānoa, 2000 "Production and Marketing profile for Black pepper (Piper nigrum)". Cooperative Extension Service 
Table 1. Component of black pepper in $(100 \mathrm{~g})^{13}$

\begin{tabular}{ll}
\hline Component & Amount \\
\hline Water & $9.5-12.0 \mathrm{~g}$ \\
Protein & $10.9-12.7 \mathrm{~g}$ \\
Starch & $25.8-44.8$ \\
Fiber & $9.7-17.2$ \\
Ash & $3.4-6.0$ \\
Piperine (pungent) & $4.9-7.7 \%$ \\
Essential oils (odiferous) & $1.0-1.8 \%$ \\
\hline
\end{tabular}

Note: mainly monoterpene and sesquiterpene hydrocarbon

The inhibition efficiency IE\% can be calculated by using Eq. (3) where $\mathrm{W}^{0}$ and $\mathrm{W}$ are the weight of coupons in the absence and presence of the inhibitors, respectively ${ }^{14}$.

$$
I E \%=\frac{W^{o}-W}{W^{o}} \times 100
$$

Eq. (4) shows how the surface coverage ( $\Theta$ ) calculated ${ }^{15}$ :

$$
\theta=\frac{I E \%}{100}
$$

The Longmuir adsorption isotherm, which is presented by the equation.

$$
\frac{C_{i n h}}{\theta}=\frac{1}{K}+C_{i n h}
$$

Where the concentration of inhibitor $\mathrm{C}_{\mathrm{inh}}$ and $\mathrm{K}_{\mathrm{ads}}$ is the equilibrium constant for the adsorption/desorption process ${ }^{15}$. For the adsorption process, which is related to the standard free energy of adsorption ( $\Delta \mathrm{G}_{\text {ads }}^{0}$ ) can be expressed by Eq.

$$
K_{a d s}=\frac{1}{55.5} \exp \left(\frac{-\Delta G^{o}{ }_{a d s}}{R T}\right)
$$

Where $\Delta \mathrm{G}^{\circ}$ ads standard free energy ${ }^{9}$, $\mathrm{R}$ gas constant and 55.5 its molar concentration of water. According to the Van Hoff Eq. (7) $\Delta \mathrm{H}^{\mathrm{o}}$ the standard adsorption heat was evaluated ${ }^{16}$.

$$
\ln K=\frac{-\Delta H^{\circ}}{R T}+\text { cons } \tan t
$$

$\Delta \mathrm{S}^{\mathrm{o}}$ the standard entropy(16), can be calculated by using Eq. (8).

$$
\Delta G^{o}{ }_{a d s}=\Delta H^{o}{ }_{a d s}-T \Delta S^{o}{ }_{a d s}
$$

Singh in 2009 showed the calculation of the activation energy by using Eq.(9).

$$
\log (\text { C.R. })=\frac{E_{a}}{2.303 R T}+A
$$

A is Arrhenius pre-exponential factor and C.R. is corrosion rate ${ }^{17}$. An alternative formulation of Arrhenius Eq. is:

$$
C . R . .=\frac{R T}{N h} \exp \cdot\left(\frac{-\Delta H^{o}}{R T}\right) \exp \cdot\left(\frac{\Delta S^{o}}{R}\right)
$$

Where, $h$ is Plank's constant, $N$ is Avogadro's Number, $\Delta S^{*}$ the entropy of activation and $\Delta \mathrm{H}^{*}$ the enthalpy of activation ${ }^{17}$. Using Eq.11 the order of the reaction has been calculated. 


$$
\log C . R .=\lg o K+B \log C_{i n h}
$$

Where $\mathrm{K}$ is the rate constant and $\mathrm{B}$ is the reaction constant ${ }^{18}$.

\section{Experimental}

The aggressive solution $(\mathrm{HCl})$ was prepared using distilled water and commercial product to obtain $11 \%$ of acid, mild steel specimens of dimension $3.066 \times 2.079 \times 0.205 \mathrm{~cm}$ used as a test specimens., The chemical composition (W\%) of mild steel is presented in Table (2) ${ }^{19}$.

Table 2. The chemical composition of mild steel

\begin{tabular}{ccccccc}
\hline $\mathrm{Fe}$ & $\mathrm{C}$ & $\mathrm{Si}$ & $\mathrm{P}$ & $\mathrm{S}$ & $\mathrm{Mn}$ & $\mathrm{Al}$ \\
\hline 99.21 & 0.21 & 0.38 & 0.09 & 0.05 & 0.05 & 0.01 \\
\hline
\end{tabular}

Weight loss measurements

Weight loss per unit area and unit time directly determined quantity in corrosion testing. Here the test specimens were weighed before and after the exposure to the corrosion medium. On this basis one could calculate the thickness reduction as weight loss per unit area/density ${ }^{7}$. The specimens were cleaned according to ASTM standard G1-03 ${ }^{19}$. The mild steel specimens were polished mechanically using emery paper of Grade Nos. 120, 180, 320, and 1200 and washed thoroughly with deionised water and finally degreased with acetone before being immersed in acid solutions.

\section{Preparation of inhibitor}

The seeds of black pepper was collected in watch glass and dried in the shade, then grinded to powder by using mortar and pestle.

\section{Results and Discussion}

The inhibition efficiency (\%IE) obtained from weight loss method at different concentrations of inhibitors and different temperatures are shown in Figure 1.

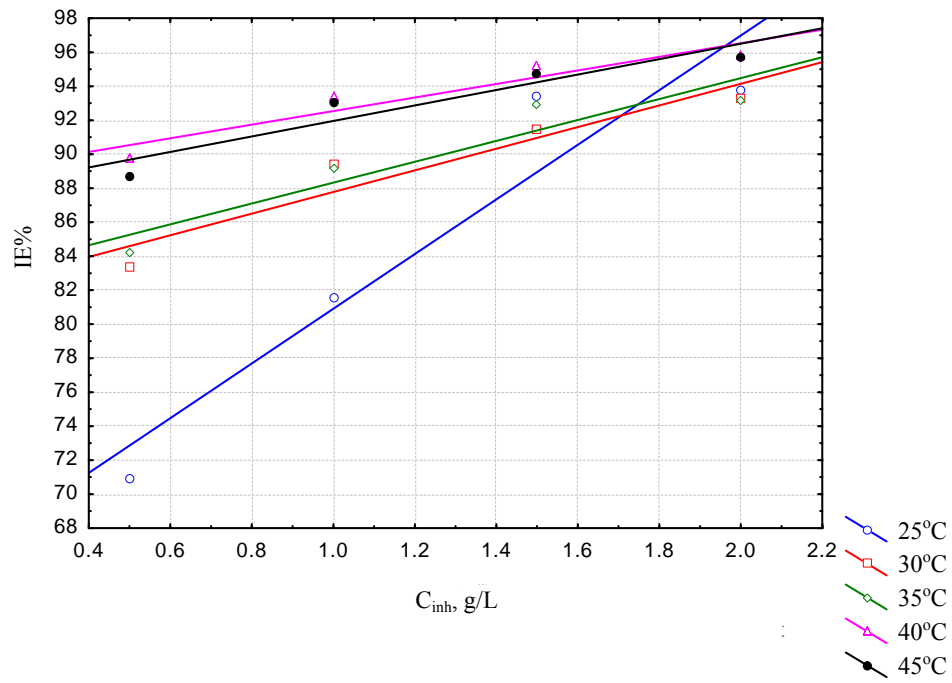

Figure 1. The relationship between IE\% and $\mathrm{C}_{\mathrm{inh}}$ in $11 \% \mathrm{HCL}$ solution at different temperature 
It has been found that the inhibition efficiency increases with increasing the concentration of the black pepper and also the efficiency of inhibition in general increasing with increasing the temperature. Plot of $\mathrm{C}_{\text {inh }} / \theta$ versus $\mathrm{C}_{\text {inh }}$ for the adsorption of black pepper on mild steel, in $11 \% \mathrm{HCl}$ shown in Figure 2.

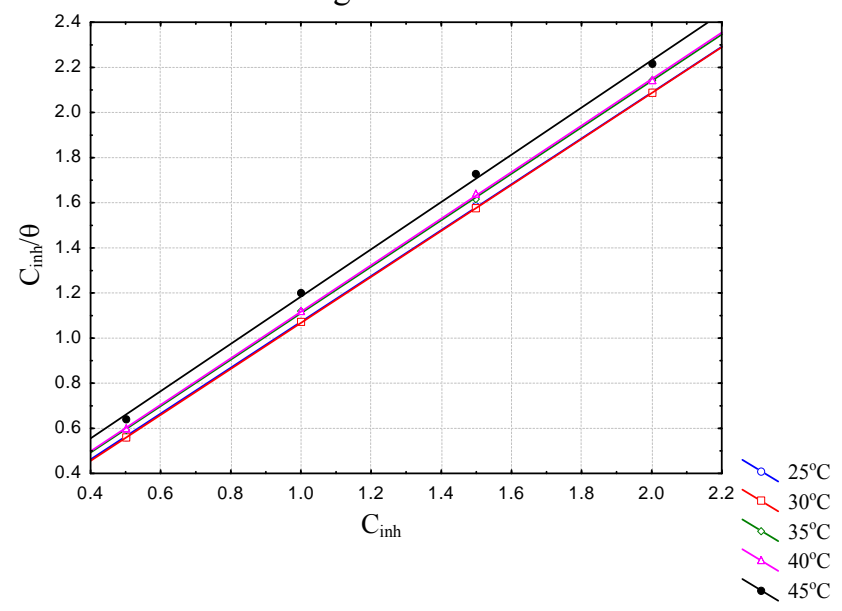

Figure 2. Adsorption isolation of blak peper on the mild steel surface in $11 \% \mathrm{HCl}$ solutions at different temperature

It can be seen from Figure 2 that a straight lines obtained which suggested that the adsorption of the black pepper follow Langmuir's isotherm. At different temperature the intercept obtained from Figure 2 and by using equations 5, 6, 7 and 8 . The values of Kads, $\Delta \mathrm{G}_{\text {ads }}^{\mathrm{o}}, \Delta \mathrm{H}^{\mathrm{o}}$ ads and $\Delta \mathrm{S}_{\text {ads }}^{\mathrm{o}}$ have been calculated, and shown in the Table 3.

Table 3. Data obtained from the Langmuir adsorption isotherm for mild steel in $11 \% \mathrm{HCl}$ in at different temperature

\begin{tabular}{ccccc}
\hline Temperature, ${ }^{\circ} \mathrm{C}$ & $\mathrm{K}_{\mathrm{ads}}$ & $\Delta \mathrm{G}^{\circ} \mathrm{kJ} / \mathrm{mol}$ & $\Delta \mathrm{H}^{\circ} \mathrm{kJ} / \mathrm{mol}$ & $\Delta \mathrm{S}^{\circ} \mathrm{J} / \mathrm{mol}$ \\
\hline 25 & 7.4 & -14.9 & -4.94 & 33.39 \\
30 & 11.62 & -16.3 & -6.18 & 33.38 \\
35 & 12.42 & -16.74 & -6.45 & 33.37 \\
40 & 20.83 & -18.36 & -7.9 & 33.40 \\
45 & 18.01 & -18.27 & -7.64 & 33.41 \\
\hline
\end{tabular}

The negative value of $\Delta \mathrm{G}_{\text {ads }}^{\mathrm{o}}$ ensure the spontaneity of the adsorption process and stability of the adsorbed layer on the mild steel surface. The calculated $\Delta \mathrm{G}_{\text {ads }}^{\mathrm{o}}$ values are around $-20 \mathrm{~kJ} / \mathrm{mol}$ indicating that the adsorption mechanism of the black pepper on mild steel in studied acid media were typical of chemisorption, the values of the thermodynamic parameter for the adsorption of inhibitors can provide valuable information ${ }^{20}$. The negative sign of $\Delta \mathrm{H}^{\circ}$ ads in the studied solutions indicates that the adsorption of inhibitor molecule is an exothermic process. Generally, an exothermic adsorption process signifies either physic- or chemisorption, the positive sign of $\Delta \mathrm{S}^{\circ}$ ads is also related to substitutional process, which can be attributed to the increase in the solvent entropy and more positive water desorption entropy. It also interpreted with increase of disorders due to the more water molecules which can be desorbed from the metal surface by one inhibitor molecule ${ }^{20}$.

The data obtained from Figure 3 are listed in Table 4 shows that the thermodynamic activation functions $\left(\mathrm{E}_{\mathrm{a}}\right)$ for the corrosion of mild steel in $11 \% \mathrm{HCl}$ solution in the presence 
of different concentration of inhibitor (black pepper) and different temperatures are lower in the presence of the inhibitors. The activation parameters were calculated using Figure 4 and Eq. (10). From the slope $\left(-\Delta \mathrm{H}^{*} / 2.0303 \mathrm{R}\right)$ and the intercept $\log \mathrm{R} / \mathrm{Nh}+\Delta \mathrm{S}^{*} / 2.303 \mathrm{R}$ the values of $\Delta \mathrm{H}^{*}$ and $\Delta \mathrm{S}^{*}$ are also listed in Table 4.

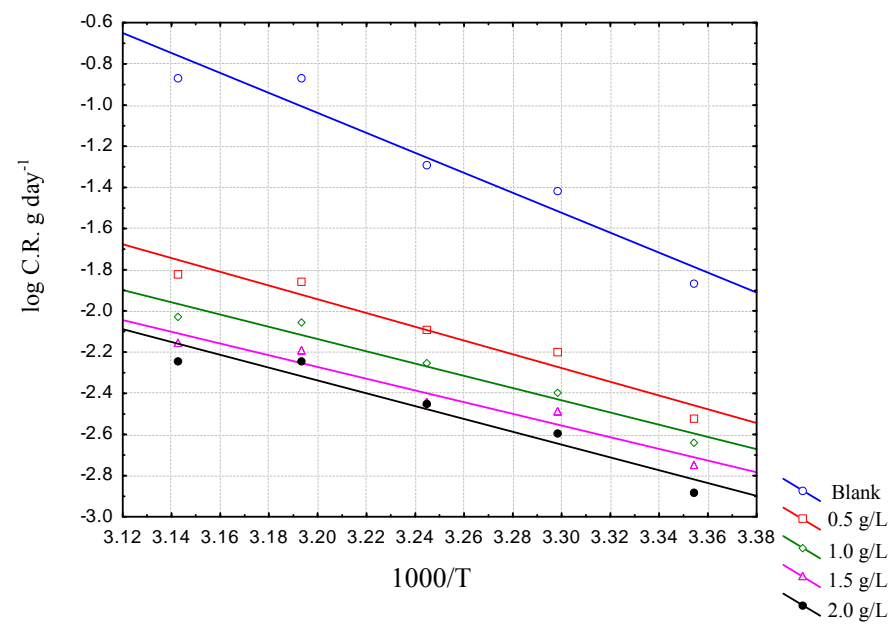

Figure 3. Adsorption isolation lot log C.R. vs. 1/T for different concentration of the inhibitor

Table 4. Thermodynamic activation parameters for mild steel in $11 \% \mathrm{HCl}$ solutions in the presence of different concentrations a black pepper

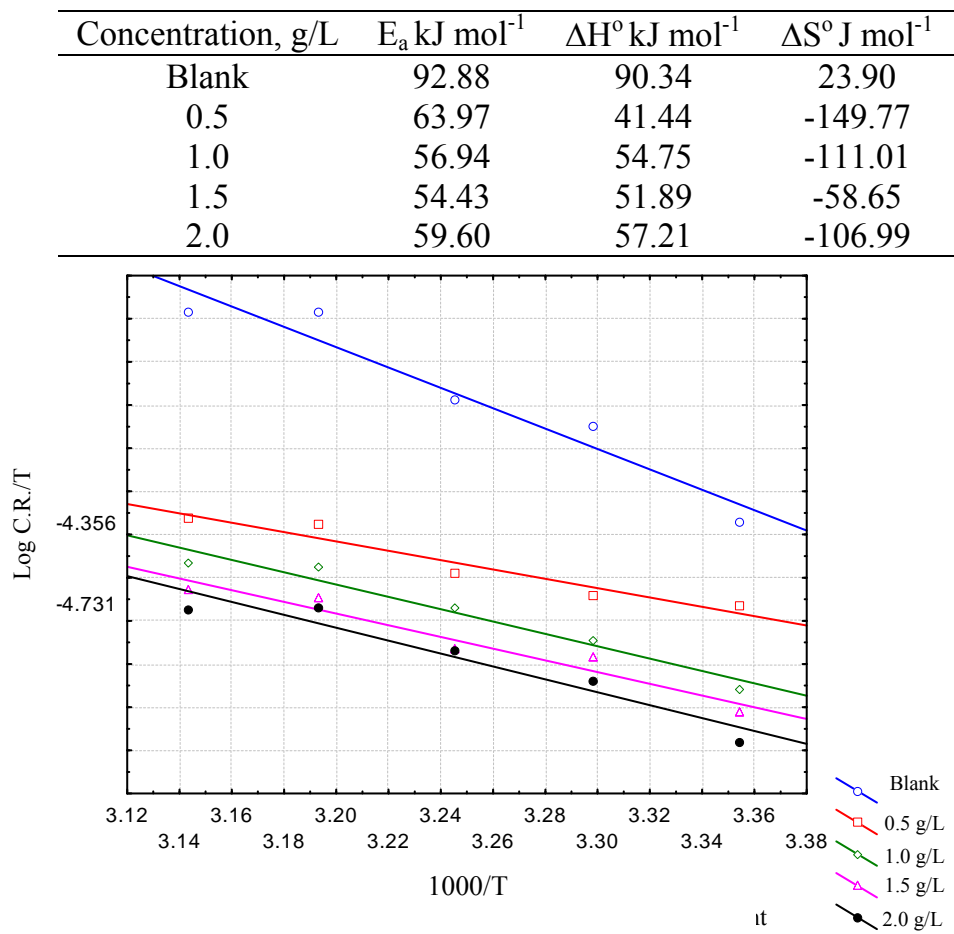

Figure 4. Adsorption isolation plot $\log ($ C.R./T) vs. 1/T for different concentration of inhibitor 
The decrease in $E_{a}$ in the presence black pepper Table 4 is give more evidence that the adsorption is chemisorptions and the positive signs of the enthalpies $\left(\Delta \mathrm{H}^{*}\right)$ reflect the endothermic nature of dissolution process of steel. The large and negative value of entropies $\left(\Delta \mathrm{S}^{*}\right)$ imply that the activated complex is the rate determining step and represents an association rather than a dissociation step ${ }^{21}$. The weight losses (gravimetric measurements) for the mild steel in $11 \%$ containing different concentrations of the black pepper as a function of time are presented in Figure 5.

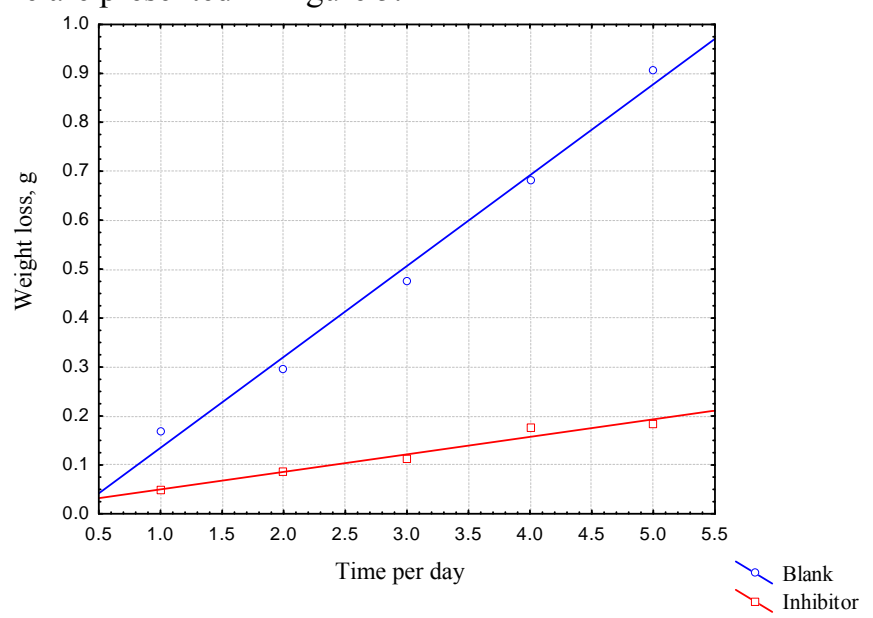

Figure 5. Variation of the weight loss vs. time for mild steel in acid solutions with and without black pepper at optimum temperature

The results show that weight losses increase with increase in time and from the weight loss data, the corrosion rate (CR.) was calculated from slop of weight loss and time. The values of corrosion rates decreased in the presence of the inhibitor (black pepper) and the corrosion rate calculated for blank is 0.1857 g.day $^{-1}$ and for the inhibited solution is 0.0357 g.day $^{-1}$ Figure 6 shows dimensional images of the surface of the mild steel in $11 \%$ $\mathrm{HCl}$ solutions in the presence and absence $2 \mathrm{~g} / \mathrm{L}$ of black pepper.

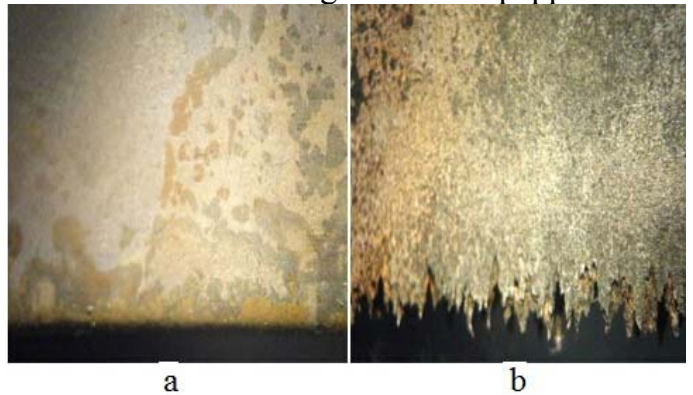

Figure 6. Two dimensional images $\mathrm{X} 12.5$ of mild steel in $11 \% \mathrm{HCl}$ solution at $45^{\circ} \mathrm{C}$ after 4 days (a) with $2 \mathrm{~g} / \mathrm{L}$ black pepper (b) without black pepper

As shown in Figure 6 the adsorption of black pepper on the surface appear clearly in a specimen (a) this will reduce the corrosion compare with specimen (b). This give more evidence the black pepper is good inhibitor in $\mathrm{HCl}$ media. Kinetic parameters are useful tool to explain the order of reaction. And the result shown in Table 5 that were calculated using Figure 7 and Eq.11. 
Table 5. Kinetic parameters for the corrosion of mild steel in $11 \%$ solutions containing black pepper at different temperatures

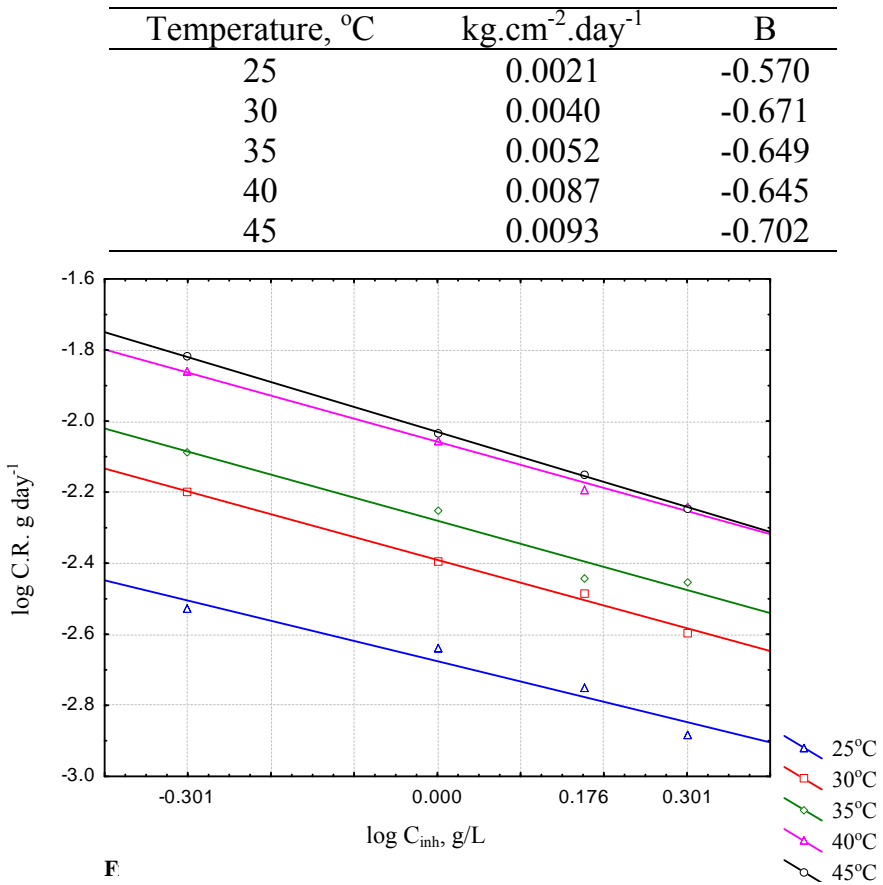

Figure 7. Plot of $\lg$ C.R. against $\log \mathrm{C}_{\text {inh }}$ for mild steel in $11 \mathrm{HCl}$ solutions, with different temperature and concentration of black pepper

The negative sign for the values of reaction constant $\mathrm{B}$ indicates that the rate of corrosion process is inversely proportional to the inhibitor concentration, meaning that the inhibitor becomes more effective with increasing its concentration. So, when the change of C.R with inhibitor concentration becomes steep (high negative value for constant B) it reflects good inhibitive properties for the studied inhibitor ${ }^{18}$. The $\mathrm{K}$ values increases with rising temperatures in $11 \% \mathrm{HCl}$ solutions.

\section{Conclusion}

- Black pepper acts as a good corrosion inhibitor for mild steel in $11 \% \mathrm{HCl}$ solutions.

- The thermodynamic adsorption parameters namely $\Delta \mathrm{G}^{\circ}, \Delta \mathrm{H}^{\circ}$ and $\Delta \mathrm{S}^{\circ}$ indicated that the adsorption of black pepper was a spontaneous and exothermic process.

- Inhibition efficiency increasing with temperatures and concentrations of inhibitor increases and decrease of $E_{a}$ in the presence of inhibitor suggesting that the adsorption of inhibitor on the surface of the mild steel is chemical adsorption.

\section{References}

1. Nestor Perez, Electrochemistry and Corrosion Science, Kluwer Academic Publishers, 2004.

2. Zhihua Tao, Shengtao Zhang, Weihua Li and Baorong Hou, Corros Sci., 2009.

3. Mars G Fontana, Corrosion Engineering., $3^{\text {rd }}$ Edition., McGraw-Hill, lnc., 1986.

4. Leila Herrag, Balkheir Hammouti, Abdelouahad Aouniti, Sghir El Kadiri and Rachid Touzani, Acta Chim Slov., 2007, 54, 419-423. 
5. Philip A Schweitzer, Fundamentals of Corrosion Mechanisms, Causes and Preventative Methods., Taylor and Francis Group., llc., 2010.

6. Tawas Plating Company and Tawas Powder Coating Inc., The Total Costs of Corrosion, 510 Industrial Avenue., Tawas City 2010.

7. Brian Derby, Corrosion and Protection, Springer Verlag London, 2004.

8. Osarolube E, Owate I O and Oforka N C, Corrosion Behaviour of Mild and High Carbon Steels in Various Acidic Media, Academic Journals, 2008.

9. Krim O, Bouachrine M, Hammouti B, Elidrissia A and Hamidi M, Portugaliae Electrochimica Acta, 2008.

10. Okafor P C, Ikpi M E, Uwah I E, Ebenso E E, Ekpe U J and Umoren S A, Corrosion Science, 2008.

11. Christensen C M, Fanse H A, Nelson G H, Fern B and Mirocha C J, Microflora of Black and Red Pepper, American Society for Microbiology, 1967.

12. Organic Farming in the Tropics and Subtropics, II Special section: Organic Cultivation of Pepper, $2^{\text {nd }}$ Edition. Naturland e.V, 2001.

13. University of Hawai'i at Mānoa, Production and Marketing profile for Black pepper (Piper nigrum). Cooperative Extension Service, 2000.

14. Weihua Li, Xia Zhao, Faqian Liu and Baorong Hou, Corros Sci., 2008, 50(11), 3261-3266; DOI:10.1016/j.corsci.2008.08.015

15. Amhmed Y Musa, Abdul Amir H Kadhum, Abu Bakar Mohamad, Abdul Razak Daud, Mohd Sobri Takriff and Siti Kartom Kamarudin, Corros Sci., 2009, 51(10), 2393-2399.

16. Libin Tang, Guannan Mu and Guangheng Liu, Corros Sci., 2003, 45(10), 2251-2262; DOI:10.1016/S0010-938X(03)00046-5

17. Ashish Kumar Singh and Quraishi M A, Corros Sci., 2009, 51(11), 2752-2760; DOI:10.1016/j.corsci.2009.07.011

18. Ehteram A Noor, Int J Electrochem Sci., 200, 2(2), 996-1017.

19. Fouad Bentiss, Charafeddine Jama, Bouchaib Mernari, Hassan El Attari, Lamia El Kadi, Mounim Lebrini, Michel Traisnel and Michel Lagrenee, Corros Sci., 2009, 51, 1628-1635; DOI:10.1016/j.corsci.2009.04.009

20. Herrag L, Chetouani A, Elkadiri S, Hammouti B and Aouniti A, Portugaliae Electrochimica Acta, 2008, 26(2), 211-220.

21. Ishtiaque Ahamad and Quraishi M A, Corros Sci., 2009, 51(9), 2006-2013; DOI:10.1016/j.corsci.2009.05.026 